\title{
Influence of Iodinated Contrast Media and Paramagnetic Contrast Media on Changes in Uptake Counts of ${ }^{99 \mathrm{~m}} \mathrm{Tc}$
}

\author{
Jae-Hwan Cho ${ }^{1}$, Jin-Hyeok Lee ${ }^{1,2}$, Cheol-Soo Park ${ }^{3}$, Sun-Yeob Lee ${ }^{3}$, \\ Jin Lee ${ }^{1}$, Deog-Hwan Moon ${ }^{4}$, and Hae-Kag Lee ${ }^{5 *}$ \\ ${ }^{1}$ Department of International Radiological Science, Hallym University of Graduate Studies, Seoul 135-841, Korea \\ ${ }^{2}$ Department of Radiology, Korea Veterans Hospital, Seoul 134-791, Korea \\ ${ }^{3}$ Department of Radiological Science, Hallym Polytechnic University, Chuncheon 200-711, Korea \\ ${ }^{4}$ Department of Public Health, Graduate School, Inje University, Busan 614-735, Korea \\ ${ }^{5}$ Department of Computer Science and Engineering, Soonchunhyang University, Asan 336-745, Korea
}

(Received 29 May 2014, Received in final form 21 June 2014, Accepted 23 June 2014)

\begin{abstract}
The purpose of this study is to figure out how uptake counts of technetium $\left({ }^{99 \mathrm{~m}} \mathrm{Tc}\right)$ among radioisotopes in the human body are affected if computed tomography (CT), magnetic resonance imaging (MRI) and isotope examination are performed consecutively. ${ }^{99 \mathrm{~m}} \mathrm{Tc}$ isotope material, iodinated contrast media for CT and paramagnetic contrast media for magnetic resonance (MR) were used as experimental materials. First, ${ }^{99 \mathrm{~m}} \mathrm{Tc}$ was added to $4 \mathrm{cc}$ normal saline in a test tube. Then, 2 cc of CT contrast media such as Iopamidol ${ }^{\circledR}$ and Dotarem $^{\circledR}$ were diluted with 2 cc normal saline, and $2 \mathrm{cc}$ of MRI contrast media such as Primovist ${ }^{\circledR}$ and Gadovist $^{\circledR}$ were diluted with 2 cc normal saline. Each distributed contrast media was a total of 4 cc and included $10 \mathrm{~m} \mathrm{Ci} \mathrm{of}{ }^{99 \mathrm{~m}} \mathrm{Tc}$. A gamma camera, a LEHR (Low energy high resolution) collimator and a pin-hole collimator were used for image acquisition. Image acquisition was repeated a total of 6 times and 120 frames were obtained and uptake counts of ${ }^{99 \mathrm{~m}} \mathrm{Tc}$ were measured (from this procedure). In this study, as a result of measuring the uptake counts of ${ }^{99 \mathrm{~m}} \mathrm{Tc}$ using the LEHR collimator, the uptake counts were less measured in all contrast media than normal saline as a reference. In particular, the lowest uptake counts were measured when Gadovist $^{\circledR}$, contrast media for MRI, was used. However, the result of measuring the uptake counts of ${ }^{99} \mathrm{~m} T \mathrm{~T}$ using the pin-hole collimator showed higher uptake counts in all contrast media, except for Iopamidol ${ }^{\circledR}$, than normal saline as a reference. The highest uptake counts were measured particularly when Primovist ${ }^{\circledR}$, contrast media for MRI, was used. In performing the gamma camera examination using contrast media and ${ }^{99 \mathrm{~m}} \mathrm{Tc}$, it is considered significant to check the changes in the uptake counts to improve various diagnosis values.
\end{abstract}

Keywords : CT contrast media, MR contrast media, ${ }^{99 \mathrm{~m}} \mathrm{Tc}$ isotope, Uptake ratio

\section{Introduction}

Recently, interest in the public health has been increasing because cerebrovascular disease and cancers are increasing as the proportion of elderly people is growing faster (than any other age group) and, in addition, the age at onset of geriatric disease is getting younger due to environment changes. Interest in public health is increasing due to the drastic increase in cerebrovascular diseases and cancer in the elderly population than in any other age group, as well as the reduced age for the onset of geriatric

(C)The Korean Magnetics Society. All rights reserved.

*Corresponding author: Tel: +82-41-530-1276

Fax: +82-41-530-1548, e-mail: lhk7083@hanmail.net diseases resulting from environmental changes. Accordingly, many kinds of diagnostic methods have been developing for early detection and diagnosis of disease, especially X-ray, CT, MRI and nuclear medicine tests have been used as a medical high-tech diagnostic method [1-4].

In X-ray, CT and MRI, contrast media is used in order to enhance the contrast of imaging. Contrast media is a substance that helps diagnose various lesions by enhancing the contrast of undistinguishable vessels and soft tissue in radiology tests. Since sodium iodide, which is effective for enhancing contrast, had been discovered in the $1920 \mathrm{~s}$, intravenous iodinated contrast media became an important factor for improving the rate of diagnosis in radiology area, and the use of this contrast media has 
been increased [5].

Different character of contrast media is used in accordance with each examination method or type of lesion. Radioisotopes are used instead of contrast media for nuclear medicine tests. Nuclear medicine test is an examination for estimating in-vivo distribution of nuclear medicine by measuring the released radiation from outside the body after radioisotopes in medicine are injected into the human body [6].

In particular, the gamma camera of nuclear medicine devices is a device for detecting two-dimensional coordinate when $\gamma$-ray photon interacts with a large-surface detector. In this device, an image is formed by accumulating many results that are acquired over a period of exposure time. Therefore, this is the examination to inspect the uptake ratio of radioisotopes in the body.

Of radioisotopes, ${ }^{99 \mathrm{~m}} \mathrm{Tc}$ materials are usually used in nuclear medicine tests. Generally, there are many factors that affect the uptake ratio in nuclear medicine tests, and the factor related to contrast media can also influence the result. There were many arguments with regard to the use of contrast media since iodinated contrast media used for positron emission tomography-computed tomography (PET-CT) can particularly affect attenuation correction [711]. However, there was no report about any influence on the uptake ratio in nuclear medicine tests other than PET/ CT.

(a)<smiles>C[C@](O)(I)[C@H]1[IH]c2c(c(I)c(C(=O)NC(CO)CO)c(I)c2C(=O)NC(CO)CO)NC1=O</smiles>

(c)

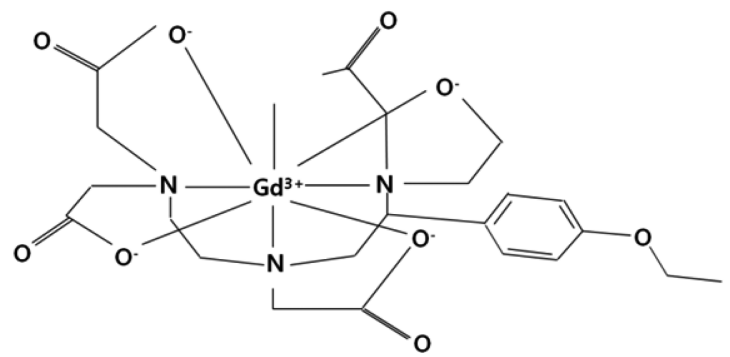

By and large, in the hospital, there are many cases where patients undergo a nuclear medicine test after CT or MRI procedures using contrast media. Particularly, of nuclear medicine tests, examinations using the gamma camera are performed most of the time. Accordingly, this study attempts to figure out how it influences the uptake counts of ${ }^{99 \mathrm{~m}} \mathrm{Tc}$ among radioisotopes in the human body when computed tomography (CT), magnetic resonance imaging (MRI) and isotope examination are performed consecutively.

\section{Materials and Methods}

\subsection{Materials}

${ }^{99 \mathrm{~m}} \mathrm{Tc}$ isotope materials eluted from molybdenumtechnetium $\left({ }^{99} \mathrm{Mo}-{ }^{99 m} \mathrm{Tc}\right)$ Generator, iodinated contrast media for CT and paramagnetic contrast media for MRI were used as experimental materials. Contrast media is divided into 4 types: ionic monomer, ionic dimer, nonionic monomer and nonionic dimer, depending the on chemical structure. In this study, nonionic contrast media such as Iopamidol ${ }^{\circledR}$ (Bracco imaging S.P.A., Italy) and Dotarem $^{\circledR}$ (Guerbet, USA) were used for CT. Nonionic contrast media is hypo-osmotic contrast media where/in which amino group is replaced by carboxylic acid radical. Nonionic contrast media such as Primovist ${ }^{\circledR}$ (Bayel, Germany) and Gadovist ${ }^{\circledR}$ (Schering, USA) were used for

(b)

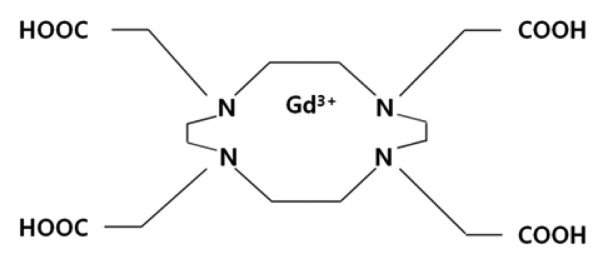

(d)

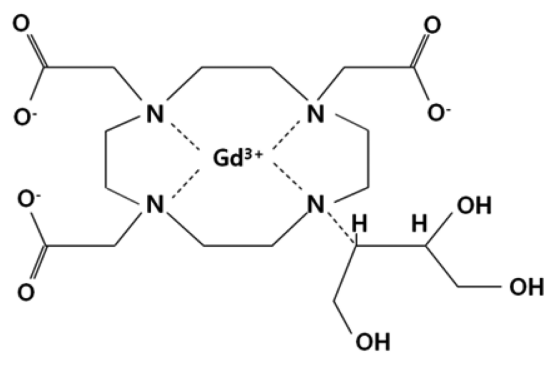

Fig. 1. In this study, nonionic contrast media such as Iopamidol ${ }^{\circledR}$ and Dotarem ${ }^{\circledR}$ were used for computed tomography. Nonionic contrast media is hypo-osmotic contrast media where/in which amino group is replaced by carboxylic acid radical. Nonionic contrast media such as Primovist ${ }^{\mathbb{B}}$ and Gadovist ${ }^{\mathbb{B}}$ were used for magnetic resonance imaging. Magnetic resonance imaging contrast media is composed of paramagnetic compounds and paramagnetic compounds contrast media represented by Gadolinium Gd3 + is $\mathrm{T}_{1}$ contrast media. 
(a)

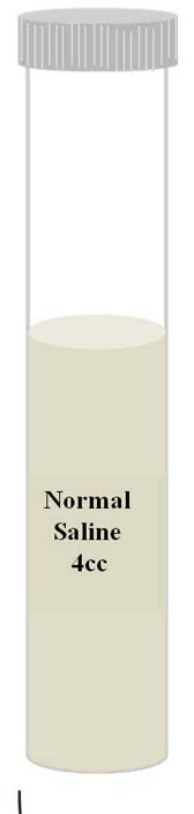

(b)

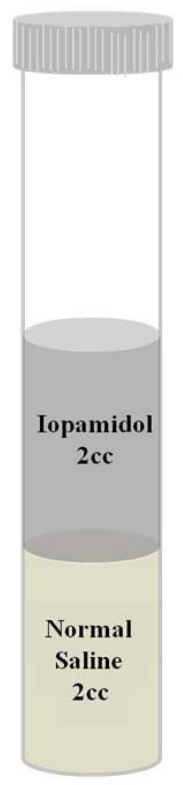

(c)

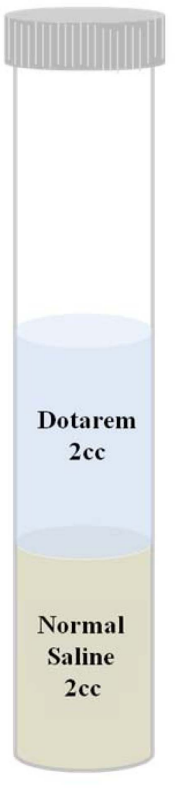

(d)

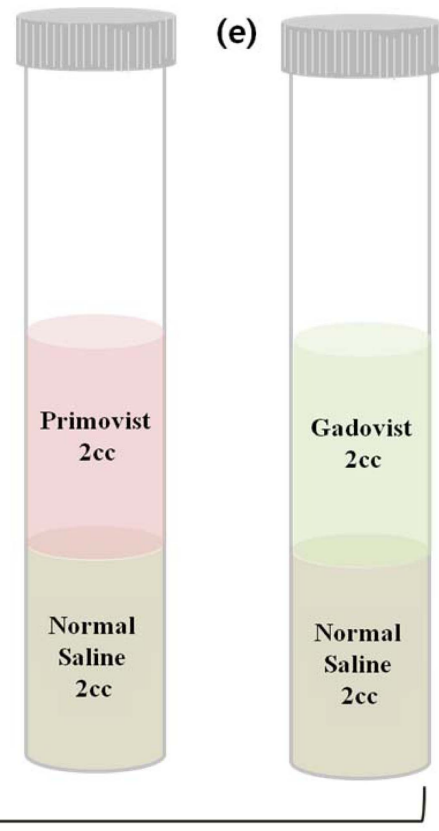

Total ${ }^{99 m} \mathrm{Tc}: 10 \mathrm{mCi}$

Fig. 2. (Color online) ${ }^{99 \mathrm{~m}} \mathrm{Tc}$ was added to $4 \mathrm{cc}$ normal saline in a test tube. Then, $2 \mathrm{cc}$ of computed tomography contrast media such as Iopamidol ${ }^{\circledR}$ and Dotarem ${ }^{\circledR}$ were diluted with $2 \mathrm{cc}$ normal saline, and $2 \mathrm{cc}$ of magnetic resonance imaging contrast media such as Primovist ${ }^{\circledR}$ and Gadovist ${ }^{\circledR}$ were diluted with $2 \mathrm{cc}$ normal saline. Each distributed contrast media was a total of $4 \mathrm{cc}$ and included $10 \mathrm{mCi}$ of ${ }^{99 \mathrm{~m}} \mathrm{Tc}$.

MRI. MRI contrast media is composed of paramagnetic compounds and paramagnetic compounds contrast media represented by Gadolinium $\mathrm{Gd}^{3+}$ is $\mathrm{T}_{1}$ contrast media. The chemical structure of CT and MRI contrast media used in this study is described in picture 1 . First, ${ }^{99 \mathrm{~m}} \mathrm{Tc}$ was added to $4 \mathrm{cc}$ normal saline in a test tube. Then, $2 \mathrm{cc}$ of $\mathrm{CT}$ contrast media such as Iopamidol ${ }^{\circledR}$ and Dotarem ${ }^{\circledR}$ were diluted with $2 \mathrm{cc}$ normal saline, and $2 \mathrm{cc}$ of MRI contrast media such as Primovist ${ }^{\circledR}$ and Gadovist ${ }^{\circledR}$ were diluted with $2 \mathrm{cc}$ normal saline. Each distributed contrast media was a total of $4 \mathrm{cc}$ and included $10 \mathrm{mCi}$ of ${ }^{99 \mathrm{~m}} \mathrm{Tc}$ (Fig. 2). Next, we carried out shaking the distributed contrast media in the test tube for 2 minutes using Biofree shaker in order to mix the contents well.

\subsection{Image Acquisition}

The gamma camera (GE Healthcare. Milwaukee. WI, USA), LEHR collimator and Pin-hole collimator were used for image acquisition. The test tube with distributed contrast media was placed at distance of $1 \mathrm{~m}$ from the bottom and $50 \mathrm{~cm}$ from the detector.

A total of 20 frames of images was obtained at a rate of 1 frame per second by each LEHR Collimator and Pinhole collimator (GE Healthcare. Milwaukee. WI, USA) with a matrix size of $128 \times 128$ and a zoom factor of 1 . This image acquisition process was repeated for a total of
6 times and a total of 120 frames was acquired. The test tube was newly made based on the same process whenever the examination was repeated since radioisotopes originally decay over a period of time.

Acquired images were transferred to Xeleris Functional Imaging Workstation (GE healthcare. Milwaukee. WI, USA) and the uptake counts of ${ }^{99 \mathrm{~m}} \mathrm{Tc}$ were estimated. The size of the region of interest (ROI) was an average of 4096 pixels and it included images as much as possible
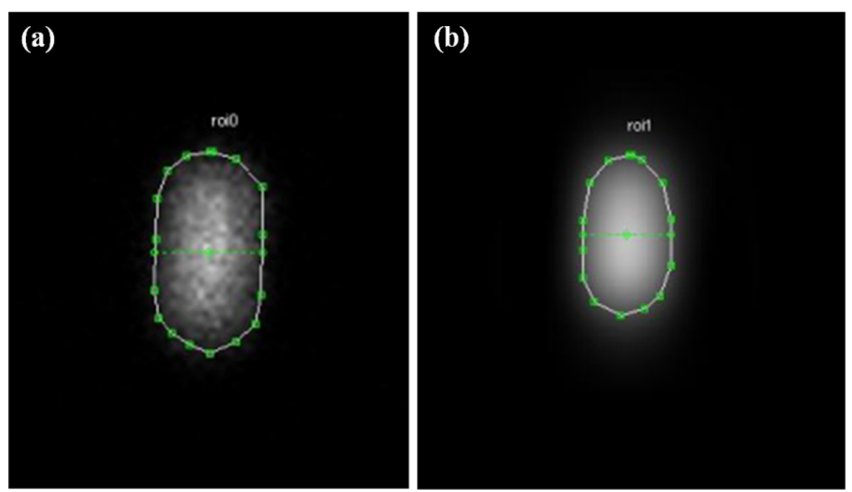

Fig. 3. (Color online) In acquired images, the uptake counts of ${ }^{99 \mathrm{~m}} \mathrm{Tc}$ were measured by low energy high resolution Collimator (a) and pin-hole collimator (b). The size of the region of interest was an average of 4096 pixels and it included as many images as possible. 
(Fig. 3).

The differences of the average values of the uptake counts measured by LEHR collimator and Pin-hole collimator in accordance with the type of contrast media were analyzed by ANOVA SPSS win 17.0 software. We assumed a statistically significant difference if $\mathrm{P}$ value is less than or equal to 0.05 . The analysis of Bland-Altman was carried out to compare the differences between the uptake counts when only normal saline was used and the uptake counts after contrast media was used.

\section{Results}

\subsection{The use of LEHR collimator}

As a result of measuring the uptake counts of ${ }^{99 m} \mathrm{Tc}$ using a LEHR collimator in accordance with the type of contrast media, the measured counts were $24757.78 \pm$ 150.57 when only normal saline was used. Besides, it was $24247.35 \pm 151.89$ when a solution diluting Iopamidol ${ }^{\circledR}$ in saline was used, $24228.27 \pm 150.85$ when a solution diluting Dotarem ${ }^{\circledR}$ in saline was used, $24405.47 \pm 151.12$ when a solution diluting Primovist ${ }^{\circledR}$ in saline was used
Table 1. The uptake counts of ${ }^{99 \mathrm{~m}} \mathrm{Tc}$ using the low energy high resolution collimator in accordance with the type of contrast media

\begin{tabular}{|c|c|c|c|}
\hline $\begin{array}{l}\text { Average }{ }^{99 \mathrm{~m}} \mathrm{Tc} \\
\text { activity }(\mathrm{mCi})\end{array}$ & Contrast media & Uptake count & $\mathrm{P}$ \\
\hline $10.15 \pm 0.02$ & Normal Saline & $24757.78 \pm 150.57$ & \\
\hline $10.20 \pm 0.02$ & Iopamidol $^{\circledR}$ & $24247.35 \pm 151.89$ & \\
\hline $10.20 \pm 0.08$ & Dotarem $^{\circledR}$ & $24228.27 \pm 150.85$ & \\
\hline $10.20 \pm 0.03$ & Primovist ${ }^{\circledR}$ & $24405.47 \pm 151.12$ & \\
\hline \multirow[t]{5}{*}{$10.20 \pm 0.03$} & Gadovist $^{\circledR}$ & $23393.94 \pm 159.33$ & 0.00 \\
\hline & Iopamidol ${ }^{\mathbb{R}}$-Normal Saline & -510.42 & \\
\hline & Dotarem ${ }^{\circledR}$-Normal Saline & -529.50 & \\
\hline & Primovist ${ }^{\mathbb{R}}$-Normal Saline & -352.30 & \\
\hline & Gadovist $^{\mathbb{R}}$-Normal Saline & -1363.84 & \\
\hline
\end{tabular}

and $23393.94 \pm 159.33$ when a solution diluting Gadovist ${ }^{\circledR}$ in saline was used.

We compared the differences among each contrast media in accordance with normal saline which is not mixed with contrast media. A solution diluting Gadovist ${ }^{\circledR}$ in saline showed the largest difference of -1363.84 compared with normal saline $(\mathrm{p}<0.01)$ (Table 1$)$. Consequently, we could
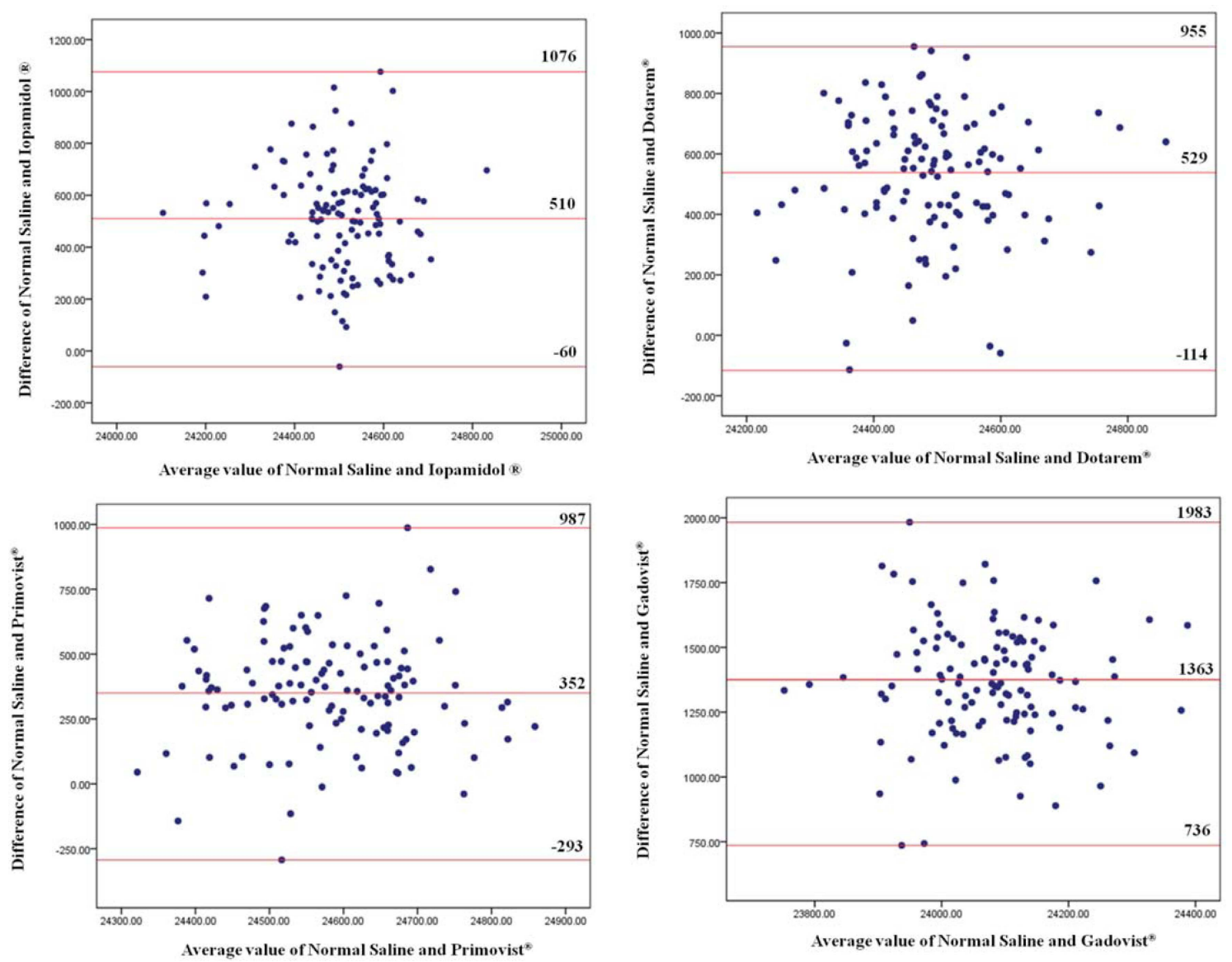

Fig. 4. (Color online) Bland-Altman analysis of the uptake counts of ${ }^{99 \mathrm{~m}} \mathrm{Tc}$ using the low energy high resolution collimator. 
Table 2. The uptake counts of ${ }^{99 \mathrm{~m}} \mathrm{Tc}$ using the pin-hole collimator in accordance with the type of contrast media

\begin{tabular}{|c|c|c|c|}
\hline $\begin{array}{l}\text { Average }{ }^{99 \mathrm{~m}} \mathrm{Tc} \\
\text { activity }(\mathrm{mCi})\end{array}$ & Contrast media & Uptake count & $P$ \\
\hline $10.26 \pm 0.05$ & Normal Saline & $1647.89 \pm 38.47$ & \\
\hline $10.29 \pm 0.03$ & Iopamidol $^{\circledR}$ & $1642.90 \pm 35.54$ & \\
\hline $10.26 \pm 0.04$ & Dotarem $^{\circledR}$ & $1662.12 \pm 42.29$ & \\
\hline $10.25 \pm 0.05$ & Primovist $^{\circledR}$ & $1665.01 \pm 39.26$ & \\
\hline \multirow[t]{5}{*}{$10.26 \pm 0.05$} & Gadovist $^{\circledR}$ & $1654.51 \pm 43.14$ & 0.000 \\
\hline & Iopamidol $^{\circledR}$-Normal Saline & -4.99 & \\
\hline & Dotarem ${ }^{\circledR}$-Normal Saline & 14.23 & \\
\hline & Primovist ${ }^{\mathbb{R}}$-Normal Saline & 17.12 & \\
\hline & Gadovist $^{\mathbb{R}}$-Normal Saline & 6.62 & \\
\hline
\end{tabular}

figure out the biggest difference in the uptake ratio when Gadovist ${ }^{\circledR}$ contrast media for MRI was used.

As a result of the Bland-Altman analysis performed, the analysis between normal saline and Iopamidol ${ }^{\circledR}$ showed limits of agreement (LOA) -60 to 1076 and the mean value of 510. The analysis between normal saline and Dotarem $^{\circledR}$ showed limits of agreement (LOA) 114 to 955 and the mean value of 529. The analysis between normal saline and Primovist ${ }^{\circledR}$ showed limits of agreement (LOA) -293 to 987 and the mean value of 352. The analysis between normal saline and Gadovist ${ }^{\circledR}$ showed limits of agreement (LOA) 736 to 1983 and the mean value of 1363 (Fig. 4).

\subsection{The use of Pin-hole collimator}

As a result of measuring the uptake counts of ${ }^{99 \mathrm{~m}} \mathrm{Tc}$ using a Pin-hole collimator in accordance with the type of contrast media, the measured counts were $1647.89 \pm$ 38.47 when only normal saline was used. Besides, it was $1642.90 \pm 35.54$ when a solution diluting Iopamidol ${ }^{\circledR}$ in saline was used, $1662.12 \pm 42.29$ when a solution diluting Dotarem $^{\circledR}$ in saline was used, $1665.01 \pm 39.26$ when a solution diluting Primovist ${ }^{\circledR}$ in saline was used and 1654.51 \pm 43.14 when a solution diluting Gadovist ${ }^{\circledR}$ in saline was used. We compared the differences among each contrast media in accordance with normal saline which is not mixed with contrast media. A solution diluting Primovist ${ }^{\circledR}$ in saline showed the largest difference of 17.12 compared with normal saline $(\mathrm{p}<0.01)$ (Table 2$)$. Consequently, we
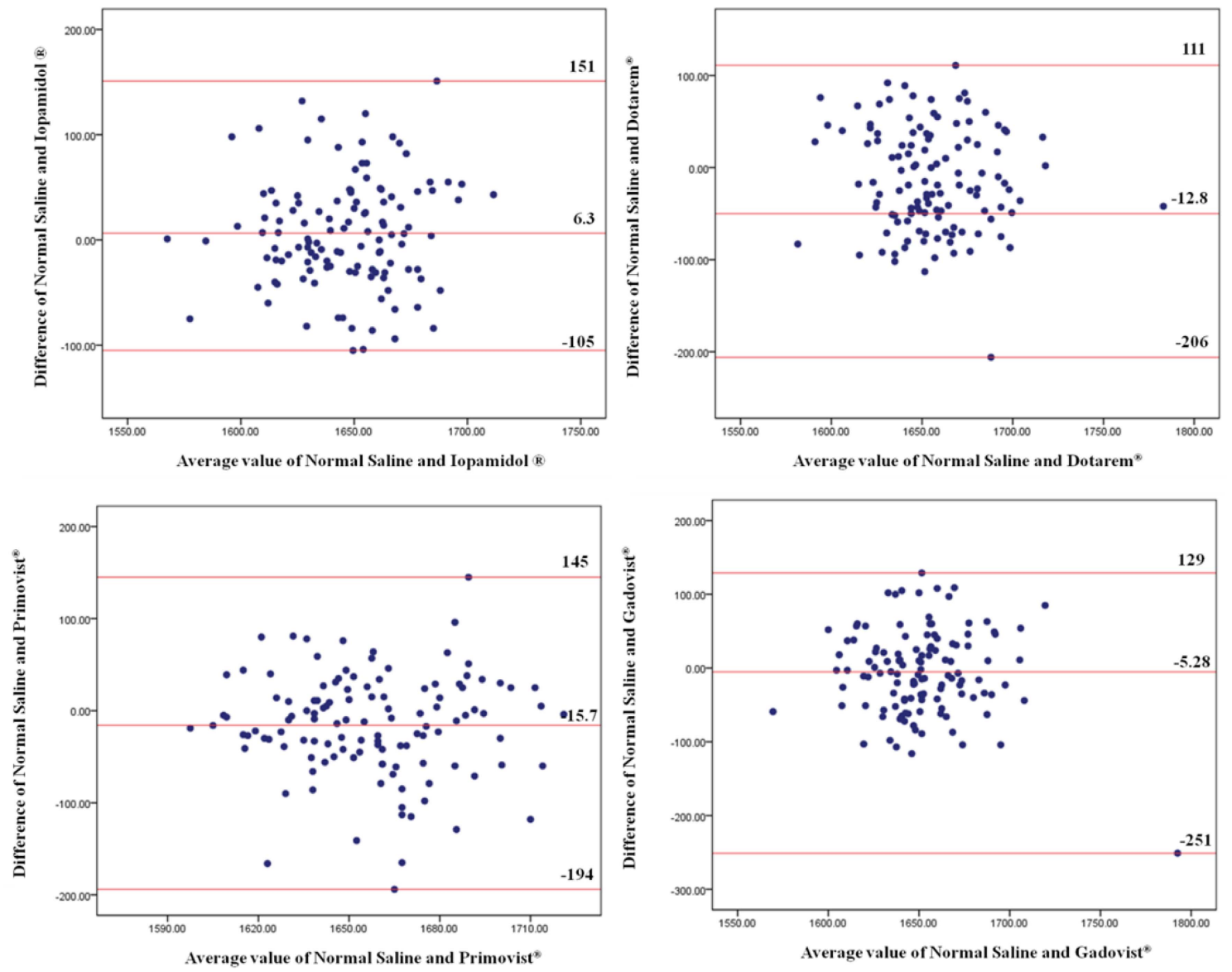

Fig. 5. (Color online) Bland-Altman analysis of the uptake counts of ${ }^{99 \mathrm{~m}} \mathrm{Tc}$ using the pin-hole collimator. 
could figure out the biggest difference in the uptake ratio when Primovist ${ }^{\circledR}$ contrast media for MRI was used.

As a result of the Bland-Altman analysis performed, the analysis between normal saline and Iopamidol ${ }^{\circledR}$ showed limits of agreement (LOA) -105 to 151 and the mean value of 6.3. The analysis between normal saline and Dotarem ${ }^{\circledR}$ showed limits of agreement (LOA) -206 to 111 and the mean value of -12.8. The analysis between normal saline and Primovist ${ }^{\circledR}$ showed limits of agreement (LOA) -194 to 145 and the mean value of 15.7. The analysis between normal saline and Gadovist $₫$ showed limits of agreement -251 to 129 and the mean value of -5.28 (Fig. 5).

Overall, as a result of measuring the uptake counts of ${ }^{99 \mathrm{~m}} \mathrm{Tc}$ using a Low energy high resolution collimator, the uptake counts were measured less in all contrast media than normal saline as a reference. Especially, the lowest uptake counts were measured when Gadovist ${ }^{\circledR}$, contrast media for MRI, was used. However, the result of measuring the uptake counts of ${ }^{99 \mathrm{~m}} \mathrm{Tc}$ using pin-hole collimator showed higher uptake counts in all contrast media, except for Iopamidol ${ }^{\circledR}$, than normal saline as a reference. The highest uptake counts were measured particularly when Primovist $^{\circledR}$, contrast media for MRI, was used. Notwithstanding the fact that the uptake counts showed a statistically significant difference, its influence on the actual diagnosis was not significant on the account of narrow limits of agreement.

\section{Discussion}

An acquisition of nuclear medicine images was begun from the first nuclear medicine scanner (Rectilinear scanner) developed by Benedict Cassen in 1951 and its clinical use was started in earnest after Hal O. Anger had pioneered the gamma camera (Anger camera) [12]. Since the 1970s, development in computer technology caused the invention and the widespread use of single photon emission computed tomography (SPECT) and positron emission tomography (PET). These days, the gamma camera with SPECT function is the most commonly used among clinical nuclear medicine imaging devices [13].

In modern healthcare, not only nuclear medicine tests but also X-ray, CT and MRI are prescribed in combination in order to improve the efficacy of diagnostic imaging. Contrast media is used especially for X-ray, CT and MRI to enhance the contrast of images. The nuclear medicine test is an examination for estimating in-vivo distribution of nuclear medicine by measuring the released radiation from outside the body after radioisotopes in medicine are injected into human body, and this test can be influenced by various factors. Hill et al. [14] reported that vasocon- striction and cellular metabolic dysfunction caused decrease in the absorption of radioactive medicine. Besides, they demonstrated that the uptake of radioactive medicine was changed in accordance with the total cholesterol, triglycerides and type of food intake.

They also reported that contrast media could be another factor. There were many arguments with regard to the use of contrast media since iodinated contrast media used for PET/CT can particularly affect attenuation correction [711]. However, there was no report about any influence on the uptake ratio in nuclear medicine tests other than PET/ CT.

Accordingly, this study attempted to figure out how it influences the uptake counts of ${ }^{99 \mathrm{~m}} \mathrm{Tc}$ among radioisotopes in the human body when CT, MRI and isotope examination are performed consecutively [15]. As a result of this study, the uptake counts were measured less in all contrast media than normal saline as a reference. Especially, the lowest uptake counts were measured when Gadovist ${ }^{\mathbb{B}}$, contrast media for MRI, was used. However, the result of measuring the uptake counts of ${ }^{99 \mathrm{~m}} \mathrm{Tc}$ using the pin-hole collimator showed higher uptake counts in all contrast media, except for Iopamidol $^{\circledR}$, than normal saline as a reference. The highest uptake counts were measured particularly when Primovist ${ }^{\mathbb{B}}$, contrast media for MRI, was used. Notwithstanding the fact that the uptake counts showed a statistically significant difference, the influence on the actual diagnosis was not significant on the account of narrow limits of agreement.

The use of the pin-hole collimator usually causes changes in sensitivity depending on the distance and the entrance size of the collimator [16]. Because of this character, the results were different from when LEHR collimator was used. Research related to nuclear medicine tests and contrast media is mostly conducted based on PET/CT. Previous studies reported that the use of contrast media improved the detection rate of liver lesions from $63 \%$ to $90 \%$ [17] and the use of contrast media resulted in $11 \%$ higher detection rate of lesions in PET/CT [18]. As reported, there are many advantages of using contrast media including easier detection of a lesion. Also, it helps figure out the shape and the range of the lesion correctly and discover the character of the lesion which is not able to be found in PET [18].

However, we could not figure out the detection rate of lesions since this study used the gamma camera instead of PET/CT and it was not performed on patients. Nevertheless, we could confirm objectively the difference in the uptake ratio in accordance with the type of contrast media. We recommend/consider a future evaluation performed on patients. 


\section{Conclusion}

In performing the gamma camera examination using ${ }^{99 \mathrm{~m}} \mathrm{Tc}$, notwithstanding the fact that the uptake counts showed a statistically significant difference in accordance with the type of contrast media, the influence on the actual diagnosis was not significant on the account of narrow limits of agreement. However, in performing the gamma camera examination using contrast media and ${ }^{99} \mathrm{~m} \mathrm{Tc}$, it is considered significant to check the changes in the uptake counts to improve various diagnosis values.

\section{Acknowledgments}

Jae-Hwan Cho and Jin-Hyeok Lee equally contributed to this work. They are co-authors of first. This work was supported in part by the Soonchunhyang university Research Fund.

\section{References}

[1] J. Cinnamon, A. B. Viroslav, and J. H. Dorey, Semin Ultrasound CT MR. 16, 212 (1995).

[2] I. Markaki, I. Franzén, C. Talani, L. Loizou, and N. Kostulas, Cerebrovasc. Dis. 35, 213 (2013).

[3] J. Vogel-Claussen, E. K. Fishman, and D. A. Bluemke, Expert Rev Cardiovasc. Ther. 5, 791 (2007).

[4] H. Hanyu, H. Arai, S. Abe, T. Iwamoto, M. Takasaki, H. Katsunuma, T. Suzuki, K. Abe, and S. Amino, Ann. Nucl. Med. 7, 45 (1993).

[5] N. O. Küçük, G. Aras, E. Ibiş, A. Soylu, N. Taşcilar, N. Yücemen, and N. Mutluer, Ann. Nucl. Med. 14, 319
(2000).

[6] T. Tsuchida, Y. Yonekura, N. Sadato, N. Takahashi, K. Yamamoto, and Y. Ishii, Ann. Nucl. Med. 13, 265 (1999).

[7] P. E. Kinahan, D. W. Townsend, T. Beyer, and D. Sashin, Attenuation correction for a combined 3D PET/CT scanner. Med. Phys. 25, 2046 (1998).

[8] D. Visvikis, D. C. Costa, I. Croasdale, A. H. Lonn, J. Bomanji, S. Gacinovic, and P. J. Ell, Eur. J. Nucl. Med. Mol. Imaging 30, 344 (2003).

[9] G. Antoch, L. S. Freudenberg, T. Egelhof, J. Stattaus, W. Jentzen, J. F. Debatin, and A. Bockisch, J. Nucl. Med. 43, 1339 (2002).

[10] Y. Nakamoto, B. B. Chin, D. L. Kraitchman, L. P. Lawler, L. T. Marshall, and R. L. Wahl, Radiology 227, 817 (2003).

[11] G. Antoch, L. S. Freudenberg, J. Stattaus, W. Jentzen, S. P. Mueller, J. F. Debatin, and A. Bockisch, Am. J. Roentgenol. 179, 1555 (2002).

[12] H. O. Anger. Rev. Sci. Inst. 29, 27 (1958).

[13] G. S. Cho, Nucl. Med. Mol. Imaging 42, 88 (2008).

[14] G. S. Hill, and R. S. Clark, Invest. Radiol. 7, 133 (1972).

[15] C. H. Chen, M. H. Huang, J. C. Yang, C. K. Nien, C. C. Yang, Y. H. Yeh, and S. K. Yueh, J. Clin. Gastroenterol. 40, 745 (2006).

[16] J. H. Kim, J. S. Lee, J. S. Kim, B. I. Lee, S. M. Kim, I. S. Choung, Y. K. Kim, W. W. Lee, S. E. Kim, J. K. Chung, M. C. Lee, and D. S. Lee, Nucl. Med. Mol. Imaging 39, 445 (2006).

[17] M. R. Violante and P. B. Dean, Radiology 134, 237 (1980).

[18] G. Antoch, L. S. Freudenberg, T. Beyer, A. Bockisch, and J. F. Debatin, J. Nucl. Med. 45, 56S (2004). 